\title{
Vinyl flooring on concrete - a moisture problem only in the Nordic countries?
}

\author{
Lars-Olof Nilsson* \\ Moistenginst AB, Trelleborg \& Lund University, Lund, Sweden
}

\begin{abstract}
I have a question to the "international community" about a moisture problem in buildings we have had in the Nordic countries for more than 50 years, and still have. It concerns moisture-induced deterioration of vinyl flooring on concrete floor slabs causing indoor air problems. Why don't you have these problems in the rest of the world (or do you)?
\end{abstract}

Peer-review under the responsibility of the organizing committee of the ICMB21.

Keywords: Vinyl flooring; concrete floors; emissions

\section{Introduction/Background}

We have had a moisture problem in buildings in the Nordic countries for more than 50 years, and still have. It concerns moisture-induced deterioration of vinyl flooring on concrete floor slabs causing indoor air problems. Our moisture problems have "developed" over time. During periods we thought we solved these problems, but then new versions of the problems appeared.

A short description is given below of how these problems have developed and the various solutions we have used. At the end the question in the title is asked and possible answers are discussed. This paper is intended as a way to get answers to this question from researchers and engineers outside the Nordic countries.

\subsection{Basic problem - vinyl flooring on partly dried concrete}

The original moisture problem from the 1970's is shown in figure 1a [1-2]. A concrete floor slab is partly dried (dashed curve). After a vinyl flooring is applied the remaining moisture in the concrete is redistributed. Eventually, the maximum $\mathrm{RH} \mathrm{RH}_{\max }$, underneath the vinyl is reached. Since the vinyl flooring had a much higher resistance, $Z_{\mathrm{PVC}}$, to moisture flow than the concrete in those days, the moisture gradient is zero in the upper part of the concrete slab. The maximum RH had to be lower than a certain acceptable level "RHOK"; 85 or $90 \%$ RH was, and is, used as that limit.

The original solution to this moisture problem was two-folded:

I. Predict the required drying time for $\mathrm{RH}$ at the depth $\mathrm{x}_{1}$ to be lower than $\mathrm{RH}_{\mathrm{OK}}$. A simple table was originally used for that prediction.

II. Determine $\mathrm{RH}$ at the depth $\mathrm{X}_{1}$ before applying the vinyl flooring. If it is lower than $\mathrm{RH}_{\mathrm{OK}}$, the flooring may be applied.

This approach worked fine for many years, after the technique to measure RH in concrete was well developed [3].

\subsection{Drying times far too long - self-desiccating concrete}

The required drying times for the concretes used in the 1970's were far too long for the building process, two to six months. Self-desiccating concrete was found to be the solution; the concrete floor could now reach below $\mathrm{RH}_{\mathrm{OK}}=85 \%$ within four weeks. A screed had to be applied at the concrete surface, however, to absorb the moisture in the water-based floor-adhesive since the low-w/c concrete could not absorb it.

(C) The Author(s). This is an open access article distributed under the terms of the Creative Commons Attribution Licence (CC BY) 4.0 https://creativecommons.org/licenses/by/4.0/, which permits unrestricted use, distribution and reproduction in any medium, provided the original author and source are credited. DOI: 10.14293/ICMB210084

\footnotetext{
${ }^{*}$ Corresponding author. +46703315365, lars-olof.nilsson@ moistenginst.se
} 

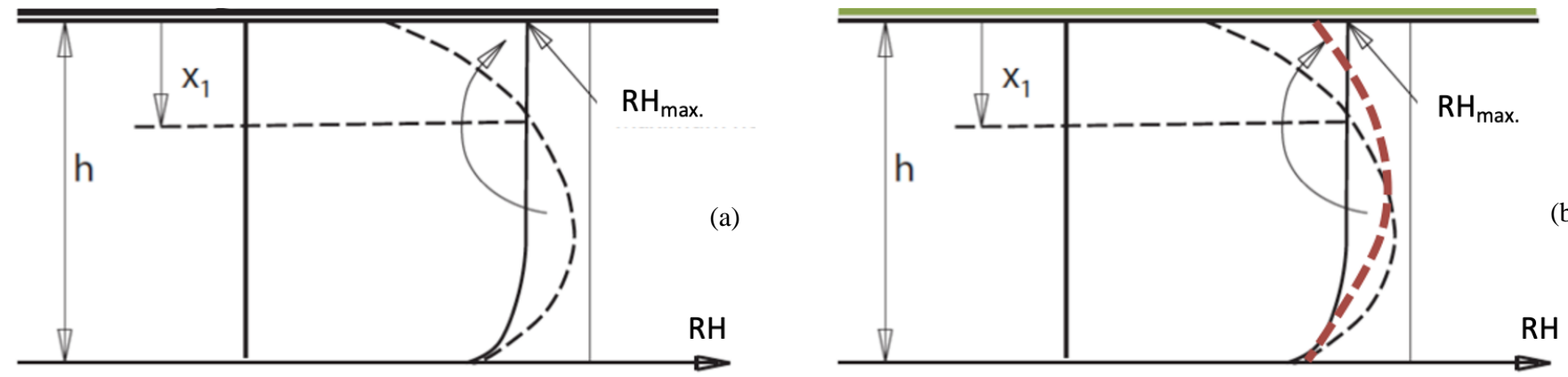

Figure 1. (a) Original problem from the 1970's; (b) Today's problem

\subsection{New technique for moisture measurements - today's self-desiccating concrete is not dry enough}

The technique to determine RH in concrete floors has developed in such a way that the measured RH has become higher and higher with this development. The acceptable limit, $\mathrm{RH}_{\mathrm{OK}}$, still is the same, however. That means that today it is very difficult to reach the acceptable limit at the depth $\mathrm{x}_{1}$ in the available time in traditional building processes.

\subsection{Low-w/c, environmental-friendly concrete - a market for moisture redistribution calculations}

The present solution to the problem where the concrete is not dry enough is to perform moisture redistribution calculations before the vinyl flooring can be applied [4]. Today's concrete has a low w/c and new binders are partly replacing the Portland cement in concrete to reduce $\mathrm{CO}_{2}$-emissions. Concretes like that may have a resistance to moisture flow comparable to the vinyl flooring. This means that the moisture gradient beneath the vinyl is not zero anymore, cf. the thick red, dashed curve in figure $1 \mathrm{~b}$. Moisture consultants are now predicting the redistribution of the remaining moisture after drying, the black, dashed curves, to find the $\mathrm{RH}_{\max }$ beneath the vinyl and not at depth $\mathrm{x}_{1}$ as before. This is complicated but the only solution today when reduction of $\mathrm{CO}_{2}-$ emissions is equally important as avoiding moisture problems.

\subsection{Vinyl flooring on concrete in the rest of the world - why unheard of?}

We have had moisture problems with vinyl flooring on concrete in the Nordic countries, especially Sweden and Finland, for more than 50 years and we still have these problems. The consequences frequently are emissions of VOCs to the indoor air.

Why don't we hear anything from the rest of the world about moisture problems like this? Please help me to understand what we do wrong and you do differently!

Are any of these alternatives correct:
a. You don't use vinyl flooring.
b. Your building processes are long enough for concrete to get dry enough.
c. You can accept the emissions of VOCs.
d. You have a technique unknown to us(?). Please tell us about it!

\section{References}

[1] Nilsson, L.-O. (1977). Moisture problems at concrete floors.(in Swedish) Report TVBM-3002, Laboratory of Building Materials, Lund University, Sweden.

[2] Nilsson, L.-O. (1979). Excess moisture in concrete slabs on grade. Drying and measuring methods. Part 2: Moisture measurements. (in Swedish) Report TVBM-3008, Laboratory of Building Materials, Lund University, Sweden

[3] Nilsson, L-O., \& Åhs, M. (2010). Methods for measuring relative humidity $(R H)$ in concrete floors - development and uncertainties. In Proceedings of Aquametry. Weimar, Germany.

[4] Nilsson, L-O., Olsson, N., Mundt-Petersen, S.O., Lindmark, S., Lindskog, M., Kumlin, A., Oxfall, M. \& Tannfors, J. (2021). Modelling the moisture redistribution in concrete floors with screed and flooring material with varying properties. In Proceedings of Nordic Symposium on Building Physics, Tallin Estonia. 